\title{
Mercantilização do ensino superior: uma análise sob a ótica dos coordenadores de curso de instituição privada
}

Após a Reforma política do Estado em 1990, houve uma propagação do ensino superior no país com a criação de programas que facilitassem a entrada dos alunos nos curso de ensino superior. Levando em consideração as tendências educacionais do mercado e o aumento das instituições privadas com mudanças na organização, o presente artigo tem como objetivo principal analisar como os coordenadores do ensino superior privado avaliam a crescente mercantilização das instituições educacionais. Para alcançar esse objetivo, inicialmente buscaram-se autores que abordassem os assuntos pertinentes ao tema, e de uma forma gradativa foram apresentados no referencial. Foram levantados aspectos importantes como o surgimento da mercantilização do ensino e suas principais consequências para a educação, e mais precisamente os seus impactos na função dos coordenadores de curso. A fim de um embasamento prático, para corroborar o que foi levantado na fundamentação teórica, como metodologia utilizou-se de entrevista em profundidade, com coordenadores de ensino superior de instituições privadas mercantilizadas. Os dados foram manipulados através da análise de conteúdo. Como resultado principal, essas entrevistas apontaram que $70 \%$ dos entrevistados concordam que hoje há uma crescente mercantilização do ensino e $90 \%$ concordam que esse processo compromete tanto a qualidade do ensino quanto à execução de suas funções.

Palavras-chave: Mercantilização do ensino; Ensino superior; Coordenadores de curso; Popularização do ensino.

\section{Mercantilization of higher education: an analysis under the optics of private institution coordinators}

After the Political Reform of the State in 1990, there was a spread of higher education in the country with the creation of programs that facilitated the entrance of students in the course of higher education Taking into account the educational trends of the market and the increase of private institutions with changes in the organization This article has the principal objective to analyze how the coordinators of private higher education evaluate the rising mercantilization of educational institutions. To achieve this goal, initially were researched authors that address subjects relevant to the topic, and in a gradually form they are presented in the referential. Important questions were raised, like the emergence of the mercantilization of education and the consequences for education, more precisely the impact on the function of course coordinators. In order to a practical background, to corroborate with what was approached in the theoretical grounds, it was realized a deep interview with coordinators of private higher education in mercantilizated institutions.

The data was manipulated through content analysis. As a main result, the interviews indicated that $70 \%$ of interviewed agree that today there is a growing mercantilization of education and $90 \%$ agree that this process commit the quality of teaching and the performance of their functions.

Keywords: Mercantilization of teaching; Higher education; Course coordinators; Popularization of teaching.

Topic: Teoria Geral da Administração

Reviewed anonymously in the process of blind peer

Flávia Sousa Alvim

Centro Universitário Unihorizontes, Brasil http://lattes.cnpq.br/6821628023934552 wfsalvim@gmail.com

Fernando Coutinho Garcia

Centro Universitário Unihorizontes, Brasil

http://lattes.cnpq.br/4973183681192358 fernando.coutinho@unihorizontes.br
Received: 01/05/2017

Approved: 01/07/2017
Referencing this:

ALVIN, F. S.; GARCIA, F. C.. Mercantilização do ensino superior: uma análise sob a ótica dos coordenadores de curso de instituição privada. Revista Brasileira de Administração Científica, v.8, n.2, p.1-15, 2017 DOI: http://doi.org/10.6008/SPC2179-684X.2017.002.0001

DOI: 10.6008/SPC2179-684X.2017.002.0001 


\section{INTRODUÇÃO}

A sociedade vive em constantes transformações, sejam elas econômicas, sociais ou culturais. Analisar o contexto dessas mudanças e os impactos gerados por elas torna-se necessários. Este artigo procura compreender as mudanças que ocorreram no âmbito da educação. A educação começou a mudar o seu conceito após o ano de 1990, quando o Estado passou por uma reforma política e houve uma propagação do ensino superior no Brasil, se estendendo aos dias de hoje. Período no qual ela começou a ser denominada como uma mercadoria, levando ao crescimento rápido das Instituições Privadas de Ensino Superior (CHAVES, 2010).

Por um lado houve a abertura para o mercado do ensino superior privado, e por outro, o governo visando uma democratização do acesso à educação superior, a fim de inserir o indivíduo nas universidades instituiu programas para inserção destes alunos nas instituições privadas como Programa Universidade para Todos (PROUNI), Fundo de Financiamento Estudantil (FIES) entre outros programas para incentivar o crescimento dos cursos e o aumento do número de estudantes.

As instituições privadas de ensino superior foram estimuladas, pelos governos, a se expandir, por meio da liberalização dos serviços educacionais e da isenção fiscal, em especial, da oferta de cursos aligeirados, voltados apenas para o ensino desvinculado da pesquisa. (CHAVES, 2010)

Mas ao analisar o cenário, tem-se aí uma abertura de mercado e agora uma visível 'facilidade de acesso' dos alunos a essas instituições privadas, tornando o ensino atrativo para os investidores. Oliveira et al. (2014) concorda ao reforçar que os universitários são vistos como mera mercadoria que futuramente estará à disposição do mercado de trabalho, ratifica-se que a sua formação profissional distanciou-se da produção científica, da formação moral, ética e do pensamento crítico, visando apenas atender as necessidades do mercado, o que resulta em indivíduos alienados, simples receptores e divulgadores de conhecimentos, incapazes de desenvolver uma análise reflexiva do meio em que está inserido.

Com o aumento dos números de Instituições Privadas surge um novo modelo, denominada 'empresarial', que se caracteriza por estar voltado para o mercado e ser controlado por ele. A predominância do mercado no controle desse novo segmento do setor privado é fundamental para entender a batalha ideológica que se trava, em muitos países, em torno da chamada privatização. É preciso ter em conta que a orientação para o mercado está associada à perda de autonomia (e mesmo de influência) do corpo acadêmico no setor privado empresarial (DURHAM et al., 2000).

Diante dessas mudanças, o corpo acadêmico, mais precisamente os coordenadores, que serão o foco de estudo desse artigo, deparam-se com o cenário em que suas funções se diferem das descritas no regimento da instituição. São necessários novos conhecimentos que vão além daqueles relacionados às questões acadêmicas e pedagógicas, muda-se a postura, a relação de coordenador-instituição assim como instituição-aluno. Coordenar um curso de ensino superior exige o conhecimento das demandas existentes na área e a criação de soluções que atendam às necessidades de todo o curso e das Instituições de Ensino Superior - IES. São necessárias novas técnicas de gestão e de conhecimento que resultem em novos procedimentos acadêmicos. 
Levando em consideração as tendências educacionais do mercado e o aumento das instituições privadas com mudanças na organização retirando o poder de decisão dos coordenadores, fica o questionamento: Como os coordenadores do ensino superior privado avaliam a crescente mercantilização das instituições educacionais?

O trabalho tem como objetivo geral analisar como os coordenadores do ensino superior privado avaliam a crescente mercantilização das instituições educacionais. E como objetivos específicos: contextualizar a popularização do ensino superior atrelado ao crescimento das instituições privadas; discriminar através da percepção do coordenador os impactos causados na qualidade de ensino; e identificar se houve alterações nas funções do coordenador de curso de graduação em uma instituição de ensino, diante das mudanças geradas pela mercantilização do ensino.

\section{REVISÃO TEÓRICA}

\section{O ensino superior no Brasil}

Após a década de 90 houve uma expansão do ensino superior brasileiro devido à reforma do Estado instaurada no país, uma nova forma de Gestão da Educação, no decorrer do processo de descentralização das ações políticas, transferindo maior compromisso e autonomia à sociedade e em especial à comunidade escolar (CHAVES, 2010).

A descentralização (incluindo a instituição de unidades escolares autônomas), na década de 1990, foi colocada pelo Banco Mundial ${ }^{1}$ como uma política para a educação pública que deveria ganhar centralidade. Essa política veio acompanhada de outras diretrizes, como: prioridade para o ensino fundamental; privatização do ensino médio e superior; convocação de pais e comunidade para participar dos assuntos escolares; redefinição das atribuições do Estado; e retirada gradual da oferta de serviços públicos, como educação e saúde, entre outros. (LOCATELLI, 2011)

Neste período ocorreu a globalização do capital e a ampliação do capitalismo financeiro na qual a educação começa a ser intitulada 'mercadoria' perdendo sua característica de bem público, proporcionando um crescimento acelerado das instituições de ensino superior privado (MANGANELLI, 2008). No contexto da década de 1990, caracterizado por políticas de privatizações e desregulamentação, um dos fatores relacionados ao acelerado crescimento das IES privadas foi à promulgação da nova Lei de Diretrizes e Bases da Educação Nacional (LDB), de 1996, que flexibilizou o mercado de educação superior e trouxe inovações para o segmento educacional.

A LDB criou os centros universitários e os cursos sequenciais, permitiu substituir o vestibular por outros processos seletivos, flexibilizou os currículos e criou os cursos de tecnologia, entre outras inovações. Para Ristoff et al. (2006), a nova LDB é "o aparato legal que sintetiza o enquadramento do sistema educacional às regras de mercado". A educação superior, sobretudo o segmento privado, passou a buscar o desenvolvimento sob os aspectos determinados pela lei. Isso promoveu um 'boom' do setor no Brasil. Segundo Schwartzman et al. (2002), considerando a legislação vigente, expressa pela nova LDB, "[...] a busca

\footnotetext{
${ }^{1}$ Banco Mundial: a criação da instituição foi resultante da preocupação dos países centrais em estabelecer uma nova ordem mundial no pós-guerra sua principal função era promover a reconstrução das economias devastadas pela guerra e a concessão de empréstimos ao setor privado, na década de 70 iniciou-se os empréstimos para o ministério da educação (FURTADO, 2008).
} 
de lucro nos empreendimentos educacionais não é mais percebida como antagônica, em princípio, aos fins da educação, ainda que possa vir a sê-lo na prática - e daí a necessidade de sistemas públicos de acompanhamento e avaliação de qualidade e resultados".

A partir da flexibilização promovida pela LDB, surgiram diversos modelos e estruturas que assumiram os objetivos e os compromissos de nortear o desenvolvimento, tanto qualitativo, quanto quantitativo, da educação superior, requerendo ações conjuntas e direcionadas à consolidação de instrumentos que pudessem avaliar o desenvolvimento do processo educacional em diversos aspectos, sobretudo no ensino e na gestão. Também se destacam reflexões vinculadas à consolidação dos modelos institucionais, direcionando o ambiente complexo e competitivo que a educação superior encontra na contemporaneidade e as principais características adotadas por universidades, centros universitários e faculdades isoladas. (FRANCISCO et al., 2014).

\title{
Popularização do Ensino Superior e a ampliação do acesso às Instituições privadas
}

Segundo a Constituição Federal de 1988, no artigo 6º, no terceiro capítulo, intitulado 'direitos sociais', a educação passa a ser um direito do cidadão e no artigo 205 reforça descrevendo a educação, direito de todos e dever do Estado e da família [...] visando sua qualificação para o trabalho. Essa qualificação, atualmente uma exigência do mercado de trabalho aumenta a competitividade e faz com que o indivíduo compreenda que a formação se torna fundamental, tanto para conseguir uma oportunidade, quanto para se estabelecer no mercado de trabalho. Esse panorama acaba intensificando a busca por ensinos privados visto as facilidades de acesso proporcionadas pelas instituições privadas, levando-as a uma incontrolável expansão. (GONTIJO, 2017). São vários os aspectos no contexto econômico e político que tem proporcionado e incentivado a expansão da educação. Martins (2006) destaca o caráter global desses aspectos:

\begin{abstract}
Uma das tendências centrais do ensino superior contemporâneo, em escala internacional, diz respeito à ampliação do seu acesso, fenômeno que se iniciou a partir da segunda metade do século XX. Um conjunto de fatores tem contribuído para esse processo, tais como a valorização do conhecimento técnico e científico como um dos ingredientes centrais das sociedades modernas, pressões por direitos sociais, aspirações de mobilidade social por meio do sistema educacional, por parte dos estudantes e de suas famílias, necessidade da aquisição de competências técnicas para enfrentar um mercado de trabalho cada vez mais instável e seletivo, transformações no conteúdo das profissões, trazendo de volta para os bancos escolares uma população adulta e já integrada em atividades profissionais etc. (MARTINS, 2006)
\end{abstract}

Considerando a democratização do acesso à educação superior, o presidente Fernando Henrique Cardoso (FHC), em seu mandato, introduziu novas políticas voltadas à busca de melhoria da qualidade dos cursos e das instituições que as oferecem. Tomou medidas que se coadunam com determinada política de expansão do ensino superior, com a criação do FIES (Financiamento Estudantil) em 1999, com o objetivo de financiar total ou parcialmente o ensino superior aos estudantes desprivilegiados financeiramente, levando à proliferação de novas instituições particulares (MANGANELLI, 2008).

Manganelli (2008) afirma que as IES privadas ganharam mais evidência no mercado, atendendo a uma demanda existente de alunos com níveis mais baixos de rendas, que tem menores condições de encarar 
a concorrência no ingresso dos cursos gratuitos, associada a uma procura por alunos que já têm idade mais avançada e que são incentivados pelo mercado a retomar os estudos.

Segundo Lima (2007), o governo Lula, seguindo a política adotada no governo FHC, dentro da premissa de que a educação é um serviço não exclusivo do Estado, continuou incentivando a existência de novas IES, através de parceria pública-privadas, como o PROUNI (forma de financiamento público da educação superior que incentiva as instituições privadas a concederem vagas a alunos de baixa renda em troca de isenções fiscais); abertura do setor da educação para empresários nacionais e estrangeiros; estímulo da educação à distância, visando democratizar a o acesso à educação e a criação de fundações privadas dentro das instituições públicas de ensino superior.

Sguissardi (2015), sobre o PROUNI e o FIES, afirma que o Estado, tendo ideológica e operacionalmente dificuldade de apostar no investimento maciço na educação superior, buscou essas vias políticas focais de curto alcance, objetivando garantias de igualdade de condições de acesso, mas que não preveem igualdade de condições de permanência e, sobretudo, de sucesso no mercado de trabalho. Sobre o ensino superior no Brasil, Sguissardi (2015) aborda que o país vive um "intenso processo de transformação de um direito ou "serviço público" em "serviço comercial" ou mercadoria, isto é, que esse não seria um processo de democratização, mas de massificação mercantil".

\section{O processo de mercantilização do ensino superior privado no Brasil}

Silva (2008) disserta sobre a redução da responsabilidade do Estado, quanto ao seu compromisso com a universidade e a educação. $\mathrm{O}$ autor analisa que essa redução de responsabilidade do Estado com a universidade fez com que ela precisasse desenvolver alternativas para se manter, e a opção desenvolvida e estimulada foi sua mercadorização. Para Trindade (2001) a comercialização dos cursos de graduação está se tornando frequente e até normal aos olhos da população brasileira, deixando claro o caráter de mercadoria atribuído à educação, e ainda afirma que:

[...] investir em Educação Superior tornou-se um dos negócios mais rentáveis e, por isso, o Brasil tornou-se o grande campeão da privatização da Educação Superior na América Latina: no ranking internacional sua posição é o 7ạ enquanto os Estados Unidos é o 20 ํㅡ na matrícula no setor privado. (TRINDADE, 2001)

O fenômeno da mercadorização se deu em duas fases, a primeira entre as décadas de 1980 e 1990, quando se consolidou o mercado nacional universitário, e a segunda quando emergiu o mercado transnacional da educação superior e universitária que, no final da década de 1990, transmutou-se para o Banco Mundial e para a Organização Mundial do Comércio, numa possibilidade de solução global dos problemas de educação. Assim, a capacidade de produzir e difundir conhecimento e informação e de gerar novos produtos e serviços passou a se destacar no cenário econômico, levando o lastro educacional a envolver também um importante valor financeiro.

Alguns grupos privados deram início a um novo ciclo no setor educacional, realizando a abertura do capital no mercado de ações, adotando estratégias de fusões e aquisições, focando na disputa de um novo nicho, como os alunos economicamente desfavorecidos. Essa onda resultou em dinheiro novo inserido nas 
IES, através das ações comercializadas na Bolsa de Valores, tem-se a concentração de mercado. Grandes instituições como a Anhanguera, Kroton e Estácio já são considerados os maiores grupos brasileiros. Quanto mais investidores atrair, maiores serão as cobranças por resultados financeiros aceitáveis.

Diante desse cenário, outras instituições de ensino superior estão identificando nesse mercado oportunidades lucrativas, sedo alvo de novas apostas dos investidores brasileiros e estrangeiros. 'Vejo o mercado de educação como um supermercado: estou vendendo um produto, só que, em vez de vender tomate, meu produto é um assento para o aluno estudar', compara o economista Marcelo Cordeiro, da Fidúcia Asset Management, qualificado na busca de investimentos na área da educação (ERTHAL et al., 2007). Essa oportunidade de lucro fácil e alto no setor educacional do Brasil revela transformações muitas vezes silenciosas.

Alguns dos maiores grupos de ensino norte-americano detêm hoje fatias generosas do capital de instituições brasileiras. Através da privatização que ocorreu no ensino, favorece-se a entrada de franquias estrangeiras que comandam cada dia mais o ensino superior no país. Segundo Manganelli (2008) essa privatização revela "a entrada de grupos empresariais norte-americanos e ingleses, que não são grupos educacionais, mas empresas que criam franquias no mundo". Chaui complementa ainda que esse encadeamento outorga para as empresas estrangeiras o controle da formação do conhecimento que deveria ser de responsabilidade brasileira, como: 'o currículo, a bibliografia, e a contratação do corpo docente'.

Sguissardi (2015) disserta que a entrada do setor financeiro na educação superior do Brasil se iniciou com a associação da Kroton (então Pitágoras), em 2001, com o Grupo Apollo International, seguido pela compra da Universidade Anhembi-Morumbi pela Laureate, em 2006, e, especialmente, pela abertura de capital das empresas Anhanguera, Kroton, Estácio e SEB em 2007.

\section{A abertura do capital dessas empresas ao mercado de ações e a valorização destas últimas possibilitam o aumento de seu capital, a compra de outras instituições menores, espalhadas no país, e, com isso, a formação de grandes grupos empresariais, também denominados 'redes' [...]. (SGUISSARDI, 2015)}

À medida que essas IES tornam-se empresas de capital aberto, com novos acionistas que em sua maioria só visam ao lucro, o fator principal dessas instituições acabam sendo negligenciados, que é o comprometimento com o ensino. Estrategicamente falando, uma das formas principais de maximizar os lucros é com a retenção de custos, e aumento da receita através de uma maior capitação de alunos. Para auxiliar nessa última estratégia tem-se o PROUNI e o FIES, mas para reduzir os custos às IES comprometem qualidade de seu ensino, dificultando cada vez mais a função do coordenador de curso, que passam a sofrer pressões idênticas às vividas por profissionais que atuam em grandes empresas.

Nesse contexto, segundo Gontijo (2017), a competitividade passou a ser o foco no meio educacional, ditando as novas condições de trabalho. As instituições educacionais elevaram o aluno aos status de cliente; dessa forma, pelas maiores exigências do mercado, este adentra uma instituição na expectativa de adquirir seu certificado, ou seja, a relação que antes era de educação, agora é substituída por uma relação mercantil. Essa relação mercantil gera impacto direto no papel do coordenador, uma vez que a alta busca pela 
competitividade intensifica a cobrança pelo alcance de metas, pela disseminação do curso de forma a atrair novos 'clientes'.

\section{Coordenadores de curso: funções e requisitos}

A Lei de Diretrizes e Bases (Lei no9.394, de 20 de dezembro 1996) extinguiu a existência de repartições nas IES. Diante disso, grande parte das instituições extinguiu-os de suas estruturas organizacionais, aderindo ao modelo de Coordenação de Curso e outorgando ao novo setor a incumbência pela gestão e pelo sucesso dos cursos superiores. Em síntese, as IES possuíam repartições em suas descrições organizacionais. Porém, a realidade é que essas repartições eram apenas setores carreiro-cêntricos, em outras palavras, um departamento destinado a cada curso existente na instituição (FRANCO, 2002).

Vasconcelos (2010) reitera que o MEC/INEP começou a exigir que as IES mantivessem em sua estrutura organizacional o coordenador de curso. E complementa ainda que esse profissional será avaliado quanto a sua dedicação, a forma como gerencia o curso e o atendimento direcionado aos seus docentes e discentes; integração institucional da coordenação; dialogicidade, transparência e liderança no exercício das funções; transitabilidade às informações; entendimento e engajamento com o Projeto Pedagógico do Curso.

Segundo Franco (2002), existem quatro condições básicas para exercer as funções de um Coordenador de Curso: quanto à qualificação, é exigido que possua a titulação de mestre ou doutor, pois segundo o MEC, esses títulos são primordiais no comando dos professores que possam ter igual qualificação; que o profissional trabalhe obedecendo ao regime mensalista de quarenta e quatro horas semanais, possibilitando um maior empenho ao seguimento do Curso; é necessário que o candidato ao cargo lecione no mínimo em duas classes para os discentes do Curso que coordena, estabelecendo uma maior conexão.

Ainda referente ao coordenador de curso, é preciso que ele seja um exemplo de professor ao corpo docente ministrando excelentes aulas, e ainda que mantenha um relacionamento acadêmico duradouro com os discentes do seu curso; e que possua eficaz capacidade gerencial de administrar o curso de maneira efetiva. Franco (2002) aborda ainda as funções de um coordenador de curso, além das descritas no regimento interno da IES:

Funções Políticas: concernentes ao perfil de líder, desenvolvendo atitudes proativas, com uma participação ativa de um agente articulador. É preciso que possua um grande conhecimento do seu público-alvo, do nicho de mercado onde está inserido, e principalmente de seu diferencial competitivo. Que seu perfil de líder seja reconhecido na área de conhecimento do seu curso, e que seja exemplo e conquiste a admiração de seus docentes e discentes;

Funções Gerenciais: a concepção e composição do Colegiado de Curso que será responsável por apoiar os coordenadores em seus processos decisórios (gerenciamento da qualidade do curso, criação das ementas e dos planos dos cursos, como as metodologias etc.);

Funções Acadêmicas: construção, efetivação, verificação e supervisão do projeto pedagógico, elaboração de atividades mais atrativas, orientação nas atividades avaliativas (Comissões Próprias de Avaliação - CPAs), observância aos prazos de publicações das notas, composição de atividades complementares, estágios supervisionados etc.;

Funções Institucionais: capacitar os discentes para que alcancem o sucesso em Exames Nacionais dos Cursos, assistirem a carreira profissional dos egressos no mercado de trabalho para examinar o grau de receptividade do curso ofertado, seguir os métodos 
requeridos pelas representantes de avaliação, para que o curso alcance a certificação e obtenha a renovação dessa certificação pelo Ministério da Educação e Cultura (MEC).

Reis (2003, citado por ARGENTA, 2012) disserta que o coordenador é o principal encarregado pelas decorrências do desempenho pedagógica e administrativo do curso. Diante disso, é necessário que se tenha a percepção da importância da articulação entre o administrativo e o pedagógico, uma vez que dependem deles o sucesso do trabalho coletivo na instituição de ensino, ocorrendo assim o partilha de responsabilidades através de uma prática mais interativa de todos.

Argenta (2012) destaca a importância do compromisso dos coordenadores, cognominados gestores universitários com a gestão das IES, priorizando a premência de instrução e qualificação para que reconheçam sua função de gestor. As principais atribuições dos gestores compreendidos pelas IES estão diretamente relacionadas a coordenar, direcionar, monitorar e liderar. Os gestores acadêmicos se caracterizam por solucionar problemas. Por outro lado, os coordenadores de curso executam mais um papel de mediação, ou ligação entre os docentes, discentes, o curso e a IES.

Com o surgimento dos grandes conglomerados educacionais, a abertura do capital na bolsa de valores e a ampliação de importantes programas do Governo Federal como o FIEM e PROUNI, foram os grandes responsáveis pela elevação do número de matrículas, transformando a atividade do coordenador de curso, de uma atividade 'fim' para uma atividade 'meio' (SILVA, 2008).

\section{A mercantilização do ensino e os novos desafios para os coordenadores de curso superior}

Com o crescimento do ensino privado e o seu processo de mercantilização, surgem novas preocupações que antes não eram consideradas como foco no âmbito educacional, aspectos relacionados às estratégias econômicas, competitividade e gerenciamento dos processos. As IES precisam adequar seu modelo de gestão profissional, assim como os atores envolvidos neste contexto, como o coordenador de curso que deixou de ter atividades meramente burocráticas, passando a exercer atividades de gestão que envolva desde a captação dos alunos até a efetividade financeira do curso (DELPINO et al., 2008).

As IES passaram a considerar o modelo gerencial como a solução para resolver todos os problemas. Foi instituída a avaliação de desempenho de professores e coordenadores, que mimetizam os processos de avaliação dos executivos, e a implementação de um modelo de plano de carreira mais parecida com o de gestores de empresas. Os alunos, nessa nova lógica, passaram a ser vistos como clientes e os cursos como produtos. Inseridos na lógica de que estão sendo avaliados a cada momento, os profissionais da educação são premiados ou punidos; muitas vezes, para mensurar esses resultados, é utilizada a pesquisa de satisfação discente, cuja lógica não é muito diferente das de pesquisa de satisfação de clientes, onde, após se consumir algo (produto/ serviço) é feita uma avaliação (ALCADIPANI, 2011, citado por GARGARY, 2016).

O desafio dos coordenadores passa a ser, portanto, o de conseguir perceber a relação entre o setor administrativo e o pedagógico, pois a coordenação representa um trabalho coletivo, cabendo a esses profissionais a responsabilidade de assegurar experiências de aprendizagem no trabalho. É necessário, pois, que o coordenador utilize ferramentas para equalizar lucratividade e qualidade de ensino (HESSEL, 2003). Porém, na realidade, o que ocorre é um choque de interesses: de um lado coordenadores preocupados com 
a qualidade de ensino e de outro os gestores acadêmicos que visam ao lucro e para alcançá-lo adotam estratégias que comprometem o padrão dos cursos.

Esse cenário atual é um risco enorme para a educação no Brasil, pois a transformação do aluno em cliente converteu o profissional da educação em um mero prestador de serviço, que, para continuar dentro do processo educacional, é forçado a ser um "animador de auditório" (ALCADIPANI, 2011, citado por GARGARY, 2016). O problema do aluno-cliente é que o ensino-aprendizado é comparado à lógica do consumo- satisfação, onde o profissional da educação não deve medir esforços para satisfazê-lo, pois a sua sobrevivência na conjuntura educacional irá depender da avaliação que este aluno irá realizar durante esse processo. Essa maneira de gerenciar as instituições corrói a essência da produção acadêmica, pois impõe uma forma de corporativismo para um tipo de atividade que pouco ou nada tem a ver com o mundo corporativo.

\section{METODOLOGIA}

A fim de analisar como os coordenadores do ensino superior privado avaliam a crescente mercantilização das instituições educacionais, e para corroborar os conceitos apresentados sobre os impactos causados na execução de suas funções, foi realizada uma pesquisa do tipo descritiva e qualitativa. Para alcançar os objetivos, foi elaborado um questionário semiestruturado, composto de 29 questões com escala tipo Likert de 5 pontos e aplicados à 10 coordenadores de curso de ensino superior privado, escolhidos de forma aleatória conforme a facilidade de acesso. Os questionários aplicados presencialmente, dando ao pesquisador a possibilidade de realizar as perguntas referentes à mercantilização em profundidade. Para análise dos dados utilizou-se da técnica de análise de conteúdo.

Mattos (2010) enfatiza que a entrevista "em profundidade" tem sido cada vez mais utilizada na pesquisa em Administração, considerando a inadequação da metodologia quantitativa à área, uma vez que muitos dos problemas e fenômenos das relações que permeiam as organizações escapam ao pesquisador quando expresso em números e estatísticas.

Quanto à entrevista em profundidade, Gil (2010) enfatiza que, de um modo geral, existem três modelos de entrevistas que podem ser utilizadas na pesquisa: entrevistas estruturadas, semiestruturadas e não estruturadas. Neste artigo foi utilizada a semiestruturada, que consiste de várias questões-chave que ajudam a definir as áreas a serem exploradas, mas também permitem o entrevistador ou entrevistado a divergirem a fim de obter uma ideia ou resposta em mais detalhes. Esta permite a descoberta ou elaboração de informações que são importantes para os participantes, mas que podem não ter sido pensadas como pertinentes pela equipe de pesquisa.

A unidade de análise deste estudo foram Instituições de Ensino Superior localizado na região metropolitana de Belo Horizonte. A unidade de observação foram os coordenadores de cursos de graduação, das IES, que tiveram o ensino mercantilizado, através de aquisições e fusões e, atualmente possuem ações na bolsa de valores, características principais desse processo de mercantilização. 
Foram considerados para essa pesquisa os coordenadores com mais de um ano na função nos cursos de graduação. Foi proposto o preenchimento do questionário para 16 coordenadores, no entanto somente 9 interessaram e se dispuseram a responder, e destes, apenas 3 responderam às perguntas em que o pesquisador propôs a profundidade.

\section{RESULTADOS E DISCUSSÃO}

\section{Dados Funcionais}

Nesta sessão serão apresentados os principais resultados da pesquisa realizada. Dos 10 questionários respondidos (60 \%) encontram-se na faixa etária de 25 a 35 anos, sendo 50\% masculino e (50\%) feminino, (70\%) possuem mestrado e apenas (20\%) não possuem a formação acadêmica condizente com o curso que coordena, (90\%) estão no cargo no período entre 2 a 6 anos, em relação a carga horária semanal houve uma variação entre 30 e 40 horas, somente $10 \%$ trabalha em outra instituição de ensino e 70 \% lecionam na instituição em que são coordenadores entre 3 a 5 disciplinas, dependendo do semestre.

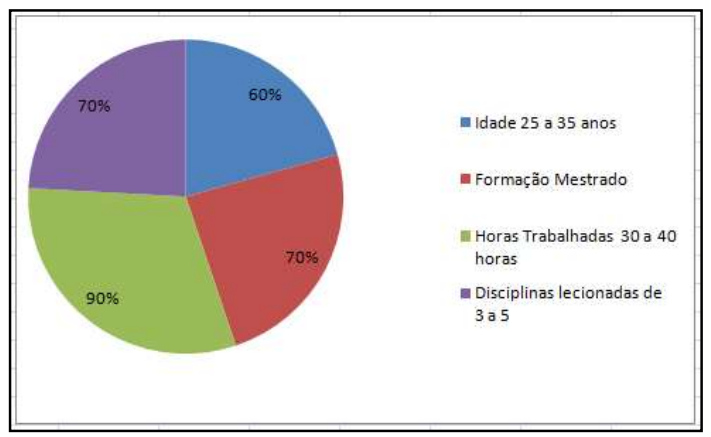

Gráfico 1: Perfil dos coordenadores.

Os resultados encontrados corroboram com Franco (2002) que descreve requisitos para se exercer a função de coordenador, para assumir o cargo é necessária a titulação de mestre ou doutor, apenas $20 \%$ dos respondentes não preencheram esta condição. Outro quesito refere-se à carga horária, para Franco (2002) o contratado deverá seguir o regime de 44 horas semanais. Na pesquisa houve uma variação entre 30 e 40 horas, sendo que (20\%) possuem um regime menor que 20 horas.

Por fim, que o indicado ministre aulas para os alunos do curso que coordena a fim de uma maior vinculação com os alunos e para proporcionar um bom exemplo aos docentes. Na pesquisa observou-se que (70\%) dos coordenadores ministram no mínimo 3 disciplinas no curso que lecionam. Com a finalidade de avaliar as questões relacionadas às ações acadêmicas, gerencias, políticas e institucionais aplicou-se uma escala tipo Likert de 5 pontos.

\section{Ações políticas}

Para se avaliar ações políticas desenvolvidas pelos coordenadores, foram realizadas perguntas referentes a atividades complementares, como seminário, palestras, pro atividade, incentivo aos docentes, marketing para alcançar novos clientes e vinculação do curso com a realidade do mercado. Dentre estes itens $60 \%$ declararam que realizam atividades complementares, $50 \%$ realizam o marketing do seu curso sendo um 
descobridor e conquistador de nichos de clientes, numa tentativa de levar as atividades acadêmicas até a sociedade. Para Nunes et al. (2015), coordenadores que se envolvem com questões denominadas políticas são mais preparados para lidar com os desafios atuais enfrentados pela educação superior privada no Brasil como a concorrência de mercado.

\section{Ações Gerenciais}

No que se refere a ações denominadas como gerenciais como proposto pela Associação Brasileira de Mantenedoras de Ensino Superior, no documento como 'construir' um coordenador ideal, destaca entre essas ações ser supervisor das instalações e equipamentos do curso, aquisição de livros, controle de frequência de discentes e docentes, contratação e demissão de docentes entre outras decisões do curso.

Segundo os respondentes da pesquisa $50 \%$ é responsável pela aquisição de livros, $40 \%$ se declara responsável pela contratação e desligamento do docente e $40 \%$ discordaram em relação ao controle da frequência do discente, não sendo esta uma responsabilidade do coordenador, os demais variaram em concordo, concordo parcialmente.

\section{Funções Acadêmicas e Institucionais}

Nas perguntas que tange as funções denominadas acadêmicas e institucionais, foram abordadas questões como: projeto pedagógico, avaliações ocorridas no curso, iniciação cientifica, acompanhamento de egressos e ENADE. Das questões respondidas apenas $40 \%$ é responsável pela elaboração do projeto pedagógico, o que corrobora com Camargos et al. (2007) "com o acúmulo de atividades e de responsabilidade, muitas vezes o coordenador se vê obrigado a privilegiar o lado gerencial, em detrimento da parte pedagógica do curso".

$60 \%$ é responsável pela qualidade e pela regularidade das avaliações desenvolvidas em seu curso. Apenas $40 \%$ incentivam a iniciação cientifica $50 \%$ se declararam concordarem parcialmente com a responsabilidade de acompanhar os egressos e 70\% concordam plenamente que são responsáveis pelo sucesso dos alunos no ENADE. Em relação à iniciação científica Oliveira et al. (2014) conclui: "[...]constata-se que a formação profissional distanciou-se da produção científica, da formação moral, ética e do pensamento crítico".

\section{Mercantilização do ensino}

Para $70 \%$ dos respondentes os coordenadores concordam que perderam a autonomia em algumas de suas decisões. Apenas um coordenador respondeu, quando questionado pelo pesquisador, o que haviam perdido: "perdemos a liberdade". A análise descritiva da amostra representada no gráfico 2 , apontam dados referentes as perguntas sobre a mercantilização, perda da autonomia, comprometimento com a qualidade de ensino e o surgimento de novas funções para os coordenadores. Sobre a mercantilização do ensino, foi questionado se os coordenadores pesquisados concordavam que hoje há uma mercantilização e 100\% responderam que concordam. 


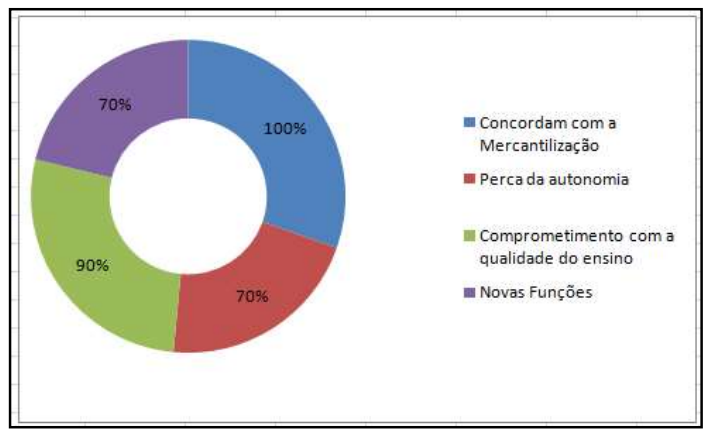

Gráfico 2: Analise descritiva da amostra.

Sobre a qualidade do ensino, objetivo do trabalho e o comprometimento de seu papel como coordenador devido o ensino está sendo ofertado como mercadoria, $90 \%$ concordam que tanto a qualidade como sua função estão comprometidas. Semelhantemente, Oliveira et al. (2012) descrevem que "a comercialização dos cursos de graduação está se tornando frequente e até normal aos olhos da população brasileira, deixando claro o caráter de mercadoria atribuído à educação". Oliveira et al. (2012) ainda descreve:

[...] sem assegurar a qualidade dos cursos, o que só tem levado a alienação e a uma internalização passiva, ao passo que as atividades acadêmicas estão totalmente direcionadas ao mercado de trabalho, se distanciando cada vez mais de uma formação humana e do pensamento crítico (emancipação humana), formando seres alienados socialmente, sendo mera fonte de lucro, uma utilidade posta no mercado de trabalho.

Essas mudanças condizem com o que foi abordado por Delpino et al. (2008), uma vez que esses aspectos apontados pelos coordenadores se referem ao novo papel exigido a eles diante do processo de mercantilização do ensino. Suas atividades, segundo Delpino et al. (2008), deixaram de serem meramente burocráticas, exigindo que adotem estratégias relacionadas aos aspectos econômicos, competitividade e gerenciamento de processos, como os exemplos citados nas entrevistas: a implementação das disciplinas EAD (Ensino a Distância), os ensalamentos que é responsável pela junção de turmas, sem se preocupar com a qualidade que fica comprometida, ambas as estratégias visam apenas redução de custos, ou seja, focando nos aspectos econômicos. Sobre a mudança na forma de atuarem $70 \%$ concordam que com a mercantilização mudou a forma de atuar trazendo novas funções, o que condiz com as respostas representadas no quadro 1.

Quadro 1: Novas funções realizadas pelo coordenador.

\begin{tabular}{|l|l|}
\hline '[...] passamos a ter funções operacionais'. & Professor 1 \\
\hline [...] temos que preocupar com a questão financeira e pessoal dos alunos'. & Professor 2. \\
\hline ' $\ldots .$.$] Evitar que ocorra desligamento e repetência [...]'.$ & Professor 2. \\
\hline '[...] Ofertar disciplinas EAD [...]'. & Professor 6. \\
\hline$'[\ldots]$ Realizar as junções de turmas, ensalamentos [...]'. & Professor 6. \\
\hline
\end{tabular}

Quanto a terem funções operacionais, está ligado ao gerenciamento de processos, na qual o coordenador passa a exercer funções que antes não era de sua competência, enquanto poderia exercer funções mais estratégicas visando à disseminação do conhecimento e fortalecimento do curso. Por fim, visando a competitividade, pode-se considerar as resposta do professor 2 , a preocupação com questões financeiras e pessoais dos alunos, bem como seu desligamento e repetência é em detrimento da competitividade, a fim de não perder esses alunos para a concorrência. 


\section{CONCLUSÕES}

Esse artigo se propôs a analisar como os coordenadores do ensino superior privado avaliam a crescente mercantilização das instituições educacionais, utilizando-se de uma pesquisa descritiva e qualitativa, buscando-se ainda um embasamento teórico que corroborasse os resultados apresentados na pesquisa, e que, sobretudo, evidenciasse os impactos causados pelo processo de mercadorização do ensino nas funções dos coordenadores.

A princípio, foi possível identificar no referencial que há uma grande preocupação acerca dos rumos que a mercantilização vem conduzindo o ensino superior. O que na visão de alguns seria uma democratização de acesso ao ensino, através das políticas expostas, como PROUNI e FIES, tornou-se verdade um dos principais gatilhos para intensificar o "boom" de crescimento das instituições privadas, após a reforma do Estado que já conduzia a educação a esse cenário. Conforme exposto por Sguissardi (2015), houve a "transformação de um direito ou 'serviço público' em "serviço comercial" ou mercadoria, isto é, que esse não seria um processo de democratização, mas de massificação mercantil".

A partir desse processo de massificação, empresas estrangeiras identificaram então no Brasil uma grande oportunidade de negócio: investir no setor da educação. Mas esse investimento não veio trazer contribuições para a pesquisa e promover a qualidade do ensino, muito pelo contrário. As estratégias de fusões e aquisições, abertura do capital por essas empresas que passaram a comercializar ações na bolsa de valores, visavam apenas retorno de investimentos, ou seja, o lucro.

Essa assertiva pode ser comprovada pelas palavras do economista Marcelo Cordeiro, principal investidor no segmento, ao comparar a educação, principal meio de desenvolvimento de um cidadão, com um mero supermercado: "Vejo o mercado de educação como um supermercado. estou vendendo um produto. Só que, em vez de vender tomate, meu produto é um assento para o aluno estudar".

A mercantilização gerou impactos negativos no ensino como um todo, uma vez que ao visar o lucro, algumas estratégias adotadas a fim de reduzir os custos podem impactar diretamente na qualidade do ensino ofertado. Alguns dos coordenadores entrevistados enfatizaram esse aspecto ao mencionar algumas estratégias adotadas pelas IES que comprometem sua qualidade, como a implementação de EADs, as junções de salas que caracterizam os ensalamentos, e o fato de procurarem evitar a repetência do aluno, ou seja, chegam até mesmo a aprovarem alunos em disciplinas que o mesmo não alcançou o desempenho necessário. Os alunos são cumulados em salas cheias, dificultando a aprendizagem e o trabalho do docente, o que interfere consideravelmente na qualidade, e ainda são obrigados a cursarem disciplinas online.

Mediante esse cenário, em resposta ao questionamento proposto: como os coordenadores do ensino superior privado avaliam a crescente mercantilização das instituições educacionais? A pesquisa apontou que $70 \%$ dos entrevistados concordam que hoje há uma crescente mercantilização do ensino, $90 \%$ concordam que esse processo compromete tanto a qualidade do ensino quanto à execução de suas funções.

Ainda sobre os coordenadores, foco principal dessa pesquisa, tanto o referencial como a entrevista identificaram mudanças nas funções exercidas por eles. A principal mudança está relacionada ao modelo gerencial que agora é adotado pelas IES, priorizando características desse perfil que antes eram apenas 
direcionados às empresas, como descrito por Hessel (2003). Aspectos relacionados a atingir metas, captação e satisfação dos alunos, rotinas administrativas e gerenciamento de processos consomem o tempo dos coordenadores, fazendo com que questões acadêmicas e pedagógicas percam espaço no dia a dia de sua profissão. Contudo, é necessária a busca de um equilíbrio entre os interesses da IES que atualmente é a busca pelo lucro, com os interesses dos coordenadores que em sua maioria é a qualidade do ensino, fazer com que as estratégias adotadas pelas instituições mercantilizadas não comprometam o padrão do curso.

Pois conforme alertado por Gargary (2016) a educação no Brasil corre um sério risco ao transformar o profissional da educação em um mero prestador de serviço, que tenha que satisfazer o aluno-cliente. Gargary (2016) finaliza enfatizando que "essa maneira de gerenciar as instituições corrói a essência da produção acadêmica, pois impõe uma forma de corporativismo para um tipo de atividade que pouco ou nada tem a ver com o mundo corporativo". Devido à relevância e amplitude do tema, sugere-se continuidade a esta pesquisa, analisando de forma mais profundos outros profissionais que também estão tendo suas funções afetadas pela mercantilização do ensino, que são os docentes.

\section{REFERÊNCIAS}

ARGENTA, C. A. L.. Gestão de instituições de ensino superior privadas e as competências necessárias aos coordenadores de curso: desafios e sugestões. Campinas: Junqueira \& Marin, 2012.

BRASIL, Lei n.9394 de 20 de dezembro de 1996. Estabelece as diretrizes e bases para a educação nacional. Brasília: DOU, 1996.

CHAVES, V. L. J.. Expansão da privatização/mercantilização do ensino superior Brasileiro: a formação dos

oligopólios. Educação \& Sociedade, v.31, n.111, p.481-500, 2010.

DELPINO, R.; CÂNDIDO, M. L. B.; MOTA, A. C.; CAMPOS, L.; DEJUSTE, M. T.. Ensino Superior: O novo perfil do coordenador de curso. ENCONTRO LATINO-AMERICANO DE INICIAÇÃO CIENTÍFICA JÚNIOR, 2. Anais. São José dos Campos: UNIVAP, 2008.

DURHAM, R. E.; SAMPAIO, H.. O setor privado de ensino superior na América Latina. Cadernos de Pesquisa, n.110, p.7-37, 2000.

ERTHAL, M. J.; PEROZIM, L.. O ensino vai à Bolsa. Revista Carta Capital, v.13, n.466, 2007.

FRANCISCO, A. H. T.; NAKAYAMA, K. M.; RAMOS, M. A.; PINTO, S. R.; RODRIGUES, M. T.. A colaboração do segmento da educação superior na proposta de democratização do acesso: um estudo da perspectiva sul catarinense. Revista GUAL, Florianópolis, v.7, n.1, p.79-105, 2014.

FRANCO, É.. Funções do Coordenador de Curso: Como Construir o Coordenador Ideal. Brasília: ABMES, 2002.

GARGARY, A.. Coordenador-Docente: os desafios do exercício simultâneo das atribuições de coordenador e docente em uma instituição de ensino superior privado. Belo Horizonte: 2016.
GIL, A. C.. Como elaborar projetos de pesquisa. 5 ed. São Paulo: Atlas, 2010.

GONTIJO, M. R.. Empresarialização das Instituições de Ensino: o impacto na vida profissional do docente do ensino superior. Revista da Faculdade de Administração e Economia, v.8, n.2, 2017

HESSEL, A. M. D. G.. Gestão de escola e tecnologia: administrativo e pedagógico, uma relação complexa. Dissertação (Mestrado em Educação) - Pontíficia Universidade Católica, São Paulo, 2003.

LIMA, K. R. S.. Contra-reforma na educação Superior: de FHC a Lula. São Paulo: Xamã, 2007.

LOCATELLI, C.. A Política de Descentralização na Educação Brasileira: resultados e consequências. In: JORNADA INTERNACIONAL DE POLÍTICAS PÚBLICAS, 5. Anais. São Luís: 2011.

MANGANELLI, A.. A mercantilização do Ensino Superior: Um olhar para os trabalhadores docentes. Revista Katálysis, v.12, n.2, p.268-277, 2008.

MARTINS, C. B.. Uma Reforma Necessária. Educação e Sociedade, Campinas, v.27, n.96, p.1001-1020, 2006.

MATTOS, P.. Pesquisa qualitativa em estudos organizacionais: paradigmas, estratégias e métodos. 2 ed. São Paulo, 2010.

NUNES, T. P.; LEÃO, J. O.. O coordenador de curso de Instituição de Ensino Superior Privado (IESP) como ferramenta de gestão estratégica: um estudo de caso em uma instituição de Montes Claros/MG. Cadernos Zygmunt Bauman, v.5, n.9, 2015.

OLIVEIRA, M. D.; TAKADA, M. Y.. A mercantilização do ensino superior. Colloquium Humanarum, v.11, p.721-728 2014. 
RISTOFF, D.; GIOLO, J.. Educação superior brasileira: 1991 a 2004. Brasília: INEP, 2006.

SCHWARTZMAN, J.; SCHWARTZMAN, S.. O ensino superior privado como setor econômico. Brasília: BNDES, 2002.

SGUISSARDI, V.. Educação superior no Brasil: Democratização ou massificação mercantil? Educação \& Sociedade, Campinas, v.36, n.133, p.867-889, 2015.
SILVA, G. J. C.. O ensino superior privado: o conflito entre lucro, expansão e qualidade. Tese (Doutorado em Sociologia) - Universidade de Brasília, Brasília, 2008.

TRINDADE, H.. As metáforas da crise: da 'universidade em ruínas' às 'universidades na penumbra' na América latina. In: GENTILI, P.. Universidades na penumbra: neoliberalismo e reestruturação universitária. São Paulo: Cortez, 2001.

VASCONCELOS, M. L. M. C.. Gestão e qualidade de ensino. In: COLOMBO, S.S. Nos bastidores da Educação Brasileira: a gestão vista por dentro. Porto Alegre: Artmed, 2010. 